\title{
HUBUNGAN BUDAYA MASYARAKAT DENGAN TINGKAT KECEMASAN PADA PASANGAN INFERTIL DI RSIA ANNISA JAMBI TAHUN 2015
}

\author{
Bri Novrika ${ }^{1}$
}

\begin{abstract}
Differences in the culture of patriarchal or matriarchal society can influence the way people view the couple with infertility problems and the importance of the existence of children in a family. This study aims to determine the relationship between the culture of the community with anxiety levels in infertile couples at RSIA Annisa Jambi. The type of this study was cross sectional, with a sample of 76 female infertile couples who experienced anxiety with total sampling technique. Data analysis with chi square test. The result of this research shows that there is a cultural relation $(p=0,000)$ with anxiety level on infertile couple. It is expected that hospitals providing infertility treatment services to provide therapy through psychiatric nursing psychoeducation therapy and / or supportive therapy to infertile couples so as to assist in minimizing the anxiety experienced and support the treatment program undergone infertile couples.
\end{abstract}

Keyword : Community culture, Anxiety, Infertile couples

\section{PENDAHULUAN}

Menurut WHO (2012), infertilitas adalah ketidakmampuan untuk hamil, ketidakmampuan mempertahankan kehamilan, ketidakmampuan untuk membawa kehamilan kepada kelahiran hidup. Infertilitas dapat bersifat primer dimana pasangan yang gagal untuk mendapatkan kehamilan sekurangkurangnya dalam satu tahun berhubungan seksual secara teratur tanpa kontrasepsi dengan angka kejadian sebanyak $62,0 \%$ dan infertilitas sekunder yaitu ketidakmampuan seseorang memiliki anak atau mempertahankan kehamilannya dengan angka kejadian sebanyak 38,0\% (Alhassan, Ziblim, $\&$ Muntaka, 2014).

WHO (2012), memperkirakan sekitar 50-80 juta pasangan mengalami infertilitas di dunia. Infertilitas di negara berkembang terjadi lebih tinggi yaitu sekitar 30\%, dibandingkan negara maju hanya 5 8\% (Masoumi, Poorolajal, \&

$1 \quad \mathrm{D}_{3} \quad$ Keperawatan, Akademi Keperawatan Jambi Yayasan Telanai Bhakti
Keramat, 2013). Prevalensi infertilitas di Asia yaitu 30,8\% di Kamboja, 10\% di Kazakhtan, 43,7\% di Turkmenistan, dan 21,3\% di Indonesia (Infertilitas, 2013).

Dari 39,8 juta Pasangan Usia Subur (PUS) di Indonesia, $10-15 \%$ diantaranya dinyatakan infertil dan diperkirakan $4-6$ juta pasangan memerlukan pengobatan infertilitas untuk mendapatkan keturunan (Rae et al., 2015). Penelitian terbaru telah menunjukkan bahwa pasangan yang mencoba untuk memiliki anak melalui pengobatan medis seperti pengobatan hormonal, inseminasi ataupun bayi tabung dinyatakan telah mengalami kecemasan (Hashemieh, Samani, \& Taghinejad, 2013). Sejalan dengan hasil penelitian (Omu \& Omu, 2010), reaksi emosional yang dialami oleh pasangan infertil adalah adalah $12,7 \%$ kecemasan pada wanita dan $6 \%$ laki-laki, $5,2 \%$ depresi pada wanita dan $14,9 \%$ pada laki-laki, $6,7 \%$ penurunan libido pada wanita dan $29,9 \%$ pada lakilaki.

Setelah pasangan infertil 161 Hubungan Budaya Masyarakat dengan Tingkat Kecemasan pada Pasangan Infertil di RSIA Annisa Jambi Tahun 2015 
menjalani pengobatan infertilitas, tingkat kecemasan yang dimiliki akan lebih meningkat dibandingkan dengan pasangan yang tidak menjalani pengobatan (Ogawa, Takamatsu, \& Horiguchi, 2011). Hal ini sejalan dengan hasil penelitian (Volgsten et al., 2010), menurut Diagnostic dan Statistik Manual of Mental Disorders edisi 4 (DSM-IV) sekitar $30 \%$ wanita dan $10 \%$ pria infertil yang menjalani pengobatan infertil mengalami kecemasan. Diperkuat dengan hasil penelitian (Coddington \& D, 2011), yang meneliti tentang perbandingan tekanan psikologis antara laki-laki dan wanita yang melakukan program Fertilisasi In Vitro (IVF), didapatkan hasil bahwa wanita secara konsisten mengalami tekanan psikologis yang mengalami gejala kecemasan lebih tinggi yaitu $96 \%$ dbandingkan pada pria $48 \%$.

Wanita adalah pihak yang sering kali mengalami perasaan tertekan pada pasangan infertilitas (Sultan \& Tahir, 2011). Perbedaan tekanan psikologis pada istri juga terlihat pada hasil penelitian (Musa et al., 2014), yang menyatakan istri secara signifikan mengalami stres $31 \%$, kecemasan $69 \%$, dan depresi $39 \%$, dan suami yang mengalami stres 23\%, kecemasan 19\%, dan depresi 19\%. Gangguan psikologis yang dialami dapat menghambat kehamilan. Tekanan jiwa pada istri akan menyebabkan terganggunya ovulasi, sel telur tidak bisa diproduksi, dimana menyebabkan saluran telur mengalami spasme sehingga sulit dilewati sel telur atau spermatozoa (Manuaba, 2010).

Ketidakmampuan wanita untuk hamil membuat wanita sering mengalami peristiwa yang tidak menyenangkan bila dibandingkan dengan pria. Hampir 70\% Wanita infertil di Andhra Pradesh India dilaporkan mengalami kekerasan fisik baik secara verbal ataupun non verbal (Sultan \& Tahir, 2011). Penelitian lain dilakukan di Pakistan mengungkapkan bahwa $69 \%$ dari wanita infertil disalahkan oleh mertua atas infertilitas yang dialaminya, diikuti $38 \%$ diceraikan atau dikirim kembali kepada orang tua mereka (Ali et al., 2011)

Kecemasan adalah rasa takut yang tidak jelas disertai dengan ketidakpastian, ketidakberdayaan, isolasi, dan ketidakamanan (Stuart, 2016). $74,6 \%$ wanita infertil dilaporkan mengalami perubahan suasana hati, merasa tidak berdaya karena durasi infertilitas yang dialaminya (Ramezanzadeh et al., 2004). Wanita infertil merasa berkurang feminitas yang dapat mengganggu harga diri dan citra dirinya sedangkan perasaan cemas membuat mereka sulit untuk berbagi perasaan dengan kerabat, sehingga muncullah perasaan kesepian dan tertekan, yang lebih lanjut membuat mereka menarik diri atau mengisolasi diri (Sultan \& Tahir, 2011).

Cemas yang dialami wanita infertil memiliki tingkatan yang berbeda-beda mulai dari yang tidak mengalami kecemasan sampai pada batas panik. Berdasarkan penelitian (Hashemieh et al., 2013), dari 100 wanita infertil, $34 \%$ responden tidak mengalami kecemasan, $34 \%$ cemas ringan, 32\% cemas tingkat sedang, dan $11 \%$ panik. Hampir sama dengan hasil penelitian (Ramezanzadeh et al., 2004), bahwa dari 370 responden, $13,2 \%$ wanita infertil tidak mengalami kecemasan, 38,1\% mengalami kecemasan sedang, $31,6 \%$ kecemasan berat, dan $17 \%$ mengalami panik.

Teori psikoanalitis klasik menyatakan bahwa pada saat individu menghadapi situasi yang dianggapnya mengancam, maka 
secara umum ia akan memiliki reaksi yang biasanya berupa rasa takut dan kebingungan menghadapi stimulus yang berlebihan dan tidak berhasil diselesaikan oleh ego, maka ego akan diliputi kecemasan (Zaviera, 2007).

Pasangan inferil, terutama wanita infertil cenderung mencari dukungan saat mengalami stres dan cemas, namun stigmatisasi yang dilakukan oleh lingkungan sekitar akan mempengaruhi harga dirinya yang dapat membuatnya malu untuk bergaul dan keluar rumah, yang akhirnya banyak wanita infertil mengucilkan diri dari acara atau pertemuan untuk menghindari kerabat ataupun teman-temannya (Tabong \& Adongo, 2013).

Budaya masyarakat yang menganggap anak adalah sebagai bentuk jaminan sosial di usia tua dan mampu mengabadikan garis keturunan keluarga, membuat pasangan infertil mengalami pandangan negatif di lingkungan masyarakat sekitarnya (Alhassan et al., 2014).

Masyarakat Indonesia yang menganut sistem kekerabatan patriarki meletakkan suami sebagai pengambil keputusan tertinggi dalam keluarga, termasuk keputusan perempuan untuk menentukan hakhak reproduksinya. Hal ini tampaknya juga akan mempengaruhi terhadap cara pandang masyarakat terhadap perempuan dengan masalah infertilitas serta arti penting keberadaan anak dalam sebuah keluarga (Koentjaraningrat, 2008).

$$
\text { Sangat berbeda dengan }
$$

masyarakat yang menganut budaya sistem kekerabatan matriarki yaitu mengambil garis keturunan ibu, perempuan dianggap kuat dan sangat dilindungi hak-hak pusaka diwariskan di tangan ibu dan anakanak (Koentjaraningrat, 2008).
Sangat penting bagi seorang perawat untuk mengidentifikasi kecemasan yang dialami oleh pasangan infertil, karena kecemasan dapat menjadi produk frustasi yang disebabkan oleh sesuatu yang mengganggu pencapaian tujuan yang diinginkan. Pandangan mereka tentang diri terancam oleh tujuan realistis mereka dan mereka mungkin akan mengalami perasaan kegagalan, tidak penting, dan kekhawatiran.

Berdasarkan studi awal peneliti di RSIA Annisa Jambi pada tanggal 14 April 2015, didapatkan hasil observasi dan wawancara dengan 5 orang wanita infertil, ada perasaan cemas, tertekan dan rendah diri yang dialami oleh kelima wanita infertil, terutama bila ditanya teman atau keluarga tentang keberadaan anak.

Kecemasan dapat menjadi faktor penting dalam keputusan klien untuk mencari, melanjutkan, ataupun menghentikan pengobatan. Pasangan infertil yang putus pengobatan akan membatasi peluang mereka hamil, sedangkan pasangan infertil yang mengalami kecemasan memiliki peluang yang lebih rendah untuk hamil (Sultan \& Tahir, 2011).

Melihat besarnya dampak kecemasan yang dialami pasangan infertil, maka peneliti tertarik untuk melakukan penelitian tentang hubungan budaya masyarakat dengan tingkat kecemasan pada pasangan infertil di RSIA Annisa Jambi tahun 2015

\section{METODE PENELITIAN}

$\begin{array}{crr}\text { Penelitian ini menggunkan } \\ \text { desain deskriptif } & \text { korelasi }\end{array}$ menggunakan jenis rancangan penelitian cross sectional. Lokasi penelitian di RSIA Annisa Jambi pada bulan Agustus 2015. Populasi dalam penelitian ini adalah seluruh wanita pasangan infertil yang sedang menjalani pengobatan infertilitas 
sebanyak 94 pasangan dengan sampel 76 responden dengan kriteria ekslusi wanita pasangan infertil yang tidak mengalami kecemasan dan wanita pasangan infertil yang mengalami depresi. Instrumen pengumpulan data menggunakan kuessioner. Saat skrinning peneliti menggunakan skala Hospital Anxiety and Depression Scale (HADS) yang telah diterjemahkan dalam bahasa Indonesia. Pengukuran tingkat kecemasan peneliti menggunakan Hamilton Anxiety Rating Scale (HARS). Pengukuran budaya masyarakat dengan merujuk pada instrumen yang digunakan sebelumnya oleh peneliti Hamzah (2013), yaitu untuk mengukur Pengaruh Budaya Patriarki Terhadap Partisipasi Politik Perempuan Di Kabupaten Nias dengan 10 item pertanyaan. Analisia data dilakukan secara univariat dan bivariat.

\section{HASIL DAN PEMBAHASAN Deskripsi Budaya Masyarakat Responden}

Tabel Distribusi Frekuensi Budaya 1 Masyarakat Responden Di RSIA Annisa Jambi Tahun 2015

\begin{tabular}{|c|c|c|c|}
\hline No. & $\begin{array}{c}\text { Budaya } \\
\text { masyarakat }\end{array}$ & f & $\%$ \\
\hline 1. & Patriarki & 40 & 52,6 \\
\hline 2. & matriarki & 36 & 47,4 \\
\hline \multicolumn{2}{|c|}{ Total } & 76 & 100 \\
\hline
\end{tabular}

Berdasarkan hasil analisis menunjukkan bahwa sebagian besar responden $(52,6 \%)$ menganut budaya patriarki terkait infertil.

\section{Deskripsi Tingkat Kecemasan Responden \\ Tabel Distribusi Frekuensi Tingkat \\ 2 Kecemasan Responden Di RSIA Annisa Jambi Tahun 2015}

\begin{tabular}{|c|l|c|c|}
\hline No. & $\begin{array}{c}\text { Tingkat } \\
\text { kecemasan }\end{array}$ & f & $\%$ \\
\hline 1. & Berat & 28 & 36,8 \\
\hline 2. & Sedang & 48 & 63,2 \\
\hline 3. & Ringan & 0 & 0 \\
\hline \multicolumn{2}{|c|}{ Total } & 76 & 100 \\
\hline
\end{tabular}

Berdasarkan hasil analisis menunjukkan bahwa sebagian besar responden $(63,2 \%)$ mengalami kecemasan sedang dan tidak ada responden $(0 \%)$ yang mengalami kecemasan ringan.

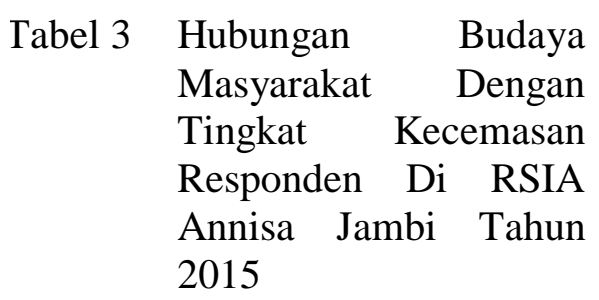

\begin{tabular}{|c|c|c|c|}
\hline & & \multirow{2}{*}{\begin{tabular}{cc}
$\begin{array}{c}\text { Kecemasa } \\
\mathrm{n}\end{array}$ & Tot \\
\cline { 1 - 2 } & al \\
Bera & Sed \\
$\mathrm{t} \quad$ ang &
\end{tabular}} & \multirow{3}{*}{$\begin{array}{cc}\mathrm{O} & P \\
\mathrm{R} & ' a l \\
& i e\end{array}$} \\
\hline & & & \\
\hline & & $\mathrm{n} \% \mathrm{n} \% \mathrm{n} \%$ & \\
\hline \multirow{6}{*}{$\begin{array}{l}\text { Buday } \\
\text { a } \\
\text { masyar } \\
\text { akat }\end{array}$} & Patriar & 133026941 & $1,61,0$ \\
\hline & ki & $7,6 \quad 3,4000$ & 800 \\
\hline & & 0 & 0 \\
\hline & & $\begin{array}{llllll}142 & 42 & 57 & 3 & 1\end{array}$ & \\
\hline & Matria & $\begin{array}{lllll}1,5 & 5,5 & 6 & 0\end{array}$ & \\
\hline & rki & 0 & \\
\hline
\end{tabular}

Hasil analisis menunjukkan sebagian besar responden $(69,4 \%)$ menganut budaya patriarki terkait infertilitas yang mengalami kecemasan sedang. Secara statistik terdapat hubungan antara budaya terkait infertilitas dengan kecemasan $(\mathrm{p}=0,000)$. Dari hasil analisis diperoleh nilai $\mathrm{OR}=1,680$, artinya wanita infertil yang menganut budaya patriarki terkait infertilitas mempunyai peluang 1,68 kali untuk mengalami kecemasan sedang. 
Berdasarkan hasil penelitian, sebagian besar wanita infertil $(69,4 \%)$ yang mengalami kecemasan sedang menganut budaya patriarki. Secara statistik terdapat hubungan yang signifikan antara budaya masyarakat dengan kecemasan $(\mathrm{p}=$ 0,000).

Menjadi ibu merupakan pusat identitas wanita dan nilai sosial, dan menjadi orang tua sepertinya lebih dihargai baik secara sosial dan material dalam keluarga besar dan masyarakat. Akibatnya, infertilitas bisa sangat menjadi sebuah stigma terutama bagi wanita, dan dapat mengakibatkan perceraian atau penambahan istri kedua (Ramezanzadeh et al., 2004).

Dalam kehidupan budaya di Indonesia nilai anak memang memiliki arti yang begitu penting. Ketiadaan anak dalam perkawinan pada waktu lama akan menjadi masalah, karena ada keyakinan keadaan ini akan mengancam keutuhan rumah tangga. Bila terjadi infertilitas pada pasangan seringkali yang disalahkan adalah kaum wanita karena kodratnya seharusnya yang mampu hamil. Padahal fungsi reproduksi sebenarnya bukan hanya milik kaum wanita saja tetapi kaum laki-laki juga memiliki kontribusi yang sama (Demartoto, 2008).

Pandangan masyarakat, lakilaki diidentifikasi sebagai makhluk yang lebih kuat dari wanita. Anak merupakan sumber kejantanan, kekuatan dan kapasitas seksual lakilaki. Dari identitas gendernya lakilaki merasa rendah ketika tidak mempunyai anak, sehingga kesalahan dilimpahkan pada pihak wanita (Demartoto, 2008).

Menurut peneliti, tingginya kecemasan pada wanita infertil yang menganut buadaya patriarki terkait infertilitasnya disebabkan karena adanya anggapan ataupun stigma di masyarakat bahwa hamil dan melahirkan itu adalah tugas wanita, sehingga wanita yang belum atau tidak memiliki anak dianggap buruk karena tidak bisa melakukan fungsinya sebagai wanita.

Banyak budaya yang masih menjamur terutama ditengah-tengah masyarakat kita yang menyatakan bahwa suatu ketidaksuburan itu merupakan tanggung jawab wanita. Nilai-nilai budaya tersebut memperkuat ketimpangan atau rasa ketidakadilan antara laki-laki dan wanita. Budaya yang dimaksud adalah budaya patriarki, dimana sistem patriarki bisa menjadi hambatan besar bagi wanita untuk mencapai ketidakadilan, mempersulit dan merugikan posisi wanita dalam kehidupan sehari-hari (Mahyuddin, 2009).

Masyarakat yang menganut sistem patriarki, meletakkan laki-laki pada posisi dan kekuasaan yang dominan dibandingkan wanita. Lakilaki dianggap memiliki kekuatan lebih dibandingkan wanita baik dalam kehidupan pribadi, keluarga, masyarakat, maupun bernegara. Kultur patriarki ini secara turuntemurun membentuk perbedaan perilaku, status, dan otoritas antara laki-laki dan wanita di masyarakat yang kemudian menjadi hirarki gender (Rueda, 2007).

\section{Saran}

1. Bagi Pemberi Pelayanan Pengobatan Infertilitas

Diharapkan bagi RSIA Annisa Jambi sebagai pemberi pelayanan pengobatan infertilitas dapat mengambil kebijakan dan keputusan yang tepat dalam pemberian asuhan keperawatan, khususnya pada kecemasan yang dialami pasangan infertil yang sedang melakukan pengobatan medis. Perawat dapat memberikan 
pendidikan kesehatan yang berkaitan dengan infertilitas dan penatalaksanaannya, dan dapat bekerjasama dengan perawat jiwa melakukan screening yang dilanjutkan dengan pemberian terapi psikoedukasi dan atau terapi supportif kepada pasangan infertil yang teridentifikasi mengalami kecemasan, sehingga dapat membantu dalam meminimalkan kecemasan dan mendukung program pengobatan yang dijalani pasangan infertil tersebut.

2. Bagi Profesi Keperawatan

Perawat jiwa dapat merekrut dan melatih kader kesehatan jiwa untuk menscreening masalah psikososial yang terjadi di masyarakat terutama kecemasan yang terjadi pada pasangan infertil yang sedang menjalani pengobatan infertilitas, sehingga program pengobatan bisa berhasil dan terwujud masyarakat yang mandiri dalam memelihara kesehatannya.

3. Bagi Peneliti selanjutnya

Diharapan kepada peneliti selanjutnya dapat melakukan penelitian secara kualitatif dengan desain grounded research agar mendapatkan hasil yang akurat dan lebih mendalam tentang hubungan budaya masyarakat dengan tingkat kecemasan.

\section{DAFTAR PUSTAKA}

Alhassan, A., Ziblim, A. R., \& Muntaka, S. (2014). A survey on depression among infertile women in Ghana. BMC Women's Health, 14(1). https://doi.org/10.1186/14726874-14-42

Ali, S., Sophie, R., Imam, A. M., Khan, F. I., Ali, S. F., Shaikh, A., \& Farid-Ul-Hasnain, S. (2011). Knowledge, perceptions and myths regarding infertility among selected adult population in Pakistan: A cross-sectional study. BMC Public Health, 11. https://doi.org/10.1186/14712458-11-760

Coddington, C., \& D, M. (2011). Comparison of multiple psychological distress measures between men and women preparing for in vitro fertilization. Fertility and Sterility, 95(2), 717-721. https://doi.org/10.1016/j.fertnst ert.2010.09.043

Demartoto, A. (2008). Dampak Infertilitas Terhadap

Perkawinan. Penelitian

Perseorangan Dalam Bidang Sosiologi Fakultas Ilmu Sosial Dan Ilmu Politik. Surakarta: Universitas Sebelas Maret.

Hashemieh, C., Samani, L. N., \& Taghinejad, H. (2013). Assessment of Anxiety in Pregnancy Following Assisted Reproductive Technology ( ART ) and Associated Infertility Factors in Women Commencing Treatment, 15(12). https://doi.org/10.5812/ircmj.1 4465

Infertilitas, K. P. (2013). Infertilitas. Himpunan Reproduksi dan Fertilitas Indonesia \& Perhimpunan Fertilitas In Vitro Indonesia.

Koentjaraningrat. (2008). Manusia Dan Kebudayaan Di Indonesia. Jakarta: Djambatan.

Mahyuddin, S. (2009). Dinamika Sistem Hukum Adat Minangkabau Dalam Yurisprudensi Mahkamah Agung. Jakart: RAJA Grafindo Persad.

Manuaba. (2010). Memahami Kesehatan Reproduksi Wanita (2nd ed.). Jakarta: EGC. 
Masoumi, S. Z., Poorolajal, J., \& Keramat, A. (2013). Prevalence of Depression among Infertile Couples in Iran: A Meta-Analysis Study, 42(5), 458-466.

Musa, R., Ramli, R., Yazmie, A. W. A., Khadijah, M. B. S., Hayati, M. Y., Midin, M., ... Ravindran, A. (2014). A preliminary study of the psychological differences in infertile couples and their relation to the coping styles. Comprehensive Psychiatry, 55(SUPPL. 1), S65-S69. https://doi.org/10.1016/j.compp sych.2013.01.001

Ogawa, M., Takamatsu, K., \& Horiguchi, F. (2011). Evaluation of factors associated with the anxiety and depression of female infertility patients, 1-5.

Omu, F. E., \& Omu, A. E. (2010). Emotional reaction to diagnosis of infertility in Kuwait and successful clients, perception of nurses , role during treatment.

Rae, L., Wiweko, B., Bell, L., Shafira, N., Pangestu, M., Adayana, I. B. P., ... Armstrong, G. (2015). Patient Education and Counseling Reproductive knowledge and patient education needs among Indonesian women infertility patients attending three fertility clinics. Patient Education and Counseling, 98(3), 364-369. https://doi.org/10.1016/j.pec.20 14.11.016

Ramezanzadeh, F., Aghssa, M. M., Abedinia, N., Zayeri, F., Khanafshar, N., Shariat, M., \& Jafarabadi, M. (2004). A survey of relationship between anxiety, depression and duration of infertility. $B M C$
Women's Health, 4, 1-7. https://doi.org/10.1186/14726874-4-9

Rueda, dkk. (2007). Feminisme Untuk Pemula. Yogyakarta: Resist Book.

Stuart. (2016). Prinsip dan Praktik Keperawatan Kesehatan Jiwa. (budi anna keliat, Ed.). Singapore Pte Ltd: Elsevier.

Sultan, S., \& Tahir, A. (2011). Psychological consequences of infertility. Hellenic Journal of Psychology, 8(2), 229-247. https://doi.org/10.1007/978-14684-5362-1_18

Tabong, P. T. N., \& Adongo, P. B. (2013). Infertility and childlessness: A qualitative study of the experiences of infertile couples in Northern Ghana. BMC Pregnancy and Childbirth, 13. https://doi.org/10.1186/14712393-13-72

Volgsten, H., Sc, M., Svanberg, S., Ph, D., Ekselius, L., \& Ph, D. (2010). Risk factors for psychiatric disorders in infertile women and men undergoing in vitro fertilization treatment, 93(4). https://doi.org/10.1016/j.fertnst ert.2008.11.008

WHO. Global Prevalence of Infrtility, Infecundity and Childlessness. (2012).

Zaviera, F. (2007). Teori Kepribadian Sigmund Freud. Yogyakarta: Prismasophie. 